\title{
Green route to synthesis of valuable chemical 6-hydroxynicotine from nicotine in tobacco wastes using genetically engineered Agrobacterium tumefaciens S33
}

Wenjun $\mathrm{Yu}^{1 \dagger}$, Rongshui Wang ${ }^{1 \dagger}$, Huili Li ${ }^{1}$, Jiyu Liang ${ }^{1}$, Yuanyuan Wang ${ }^{2}$, Haiyan Huang ${ }^{2}$, Huijun Xie ${ }^{3}$ and Shuning Wang ${ }^{1 *}$ (1)

\begin{abstract}
Background: Tobacco is widely planted as an important nonfood economic crop throughout the world, and large amounts of tobacco wastes are generated during the tobacco manufacturing process. Tobacco and its wastes contain high nicotine content. This issue has become a major concern for health and environments due to its toxicity and complex physiological effects. The microbial transformation of nicotine into valuable functionalized pyridine compounds is a promising way to utilize tobacco and its wastes as a potential biomass resource. Agrobacterium tumefaciens S33 is able to degrade nicotine via a novel hybrid of the pyridine and pyrrolidine pathways, in which several intermediates, such as 6-hydroxynicotine, can be used as renewable precursors to synthesize drugs and insecticides. This provides an opportunity to produce valuable chemical 6-hydroxynicotine from nicotine via biocatalysis using strain S33.

Results: To accumulate the intermediate 6-hydroxynicotine, we firstly identified the key enzyme decomposing 6-hydroxynicotine, named 6-hydroxynicotine oxidase, and then disrupted its encoding gene in A. tumefaciens S33. With the whole cells of the mutant as a biocatalyst, we tested the possibility to produce 6-hydroxynicotine from the nicotine of tobacco and its wastes and optimized the reaction conditions. At $30^{\circ} \mathrm{C}$ and pH 7.0, nicotine could be efficiently transformed into 6-hydroxynicotine by the whole cells cultivated with glucose/ammonium/6-hydroxy-3-succinoylpyridine medium. The molar conversion and the specific catalytic rate reached approximately $98 \%$ and $1.01 \mathrm{~g}$ 6-hydroxynicotine $\mathrm{h}^{-1} \mathrm{~g}^{-1}$ dry cells, respectively. The product could be purified easily by dichloromethane extraction with a recovery of 76.8\%, and was further confirmed by UV spectroscopy, mass spectroscopy, and NMR analysis.
\end{abstract}

Conclusions: We successfully developed a novel biocatalytic route to 6-hydroxynicotine from nicotine by blocking the nicotine catabolic pathway via gene disruption, which provides an alternative green strategy to utilize tobacco and its wastes as a biomass resource by converting nicotine into valuable hydroxylated-pyridine compounds.

Keywords: Nicotine, 6-Hydroxynicotine, 6-Hydroxynicotine oxidase, Biotransformation, Functionalized pyridine, Tobacco wastes, Agrobacterium tumefaciens

\footnotetext{
*Correspondence: shuningwang@sdu.edu.cn

tWenjun Yu and Rongshui Wang contributed equally to this work

1 State Key Laboratory of Microbial Technology, School of Life Science,

Shandong University, Jinan 250100, People's Republic of China

Full list of author information is available at the end of the article
} 


\section{Background}

Tobacco is widely planted as an important nonfood economic crop throughout the world, and large amounts of tobacco wastes are generated during the tobacco manufacturing process [1-3]. Nicotine, the main toxic alkaloid in tobacco leaves and its wastes, comprises approximately $0.6-5 \%(\mathrm{w} / \mathrm{w})$ of tobacco dry materials and is responsible for tobacco addiction and environmental threats [1, 4]. Nicotine was listed in the Toxics Release Inventory by the US Environmental Protection Agency as early as 1994. It has complex physiological effects and may cause diseases such as cancer [5-7]. Thus, the treatment of nicotine becomes the major concern for tobacco waste disposal. In 2003, the WHO framework convention on tobacco control led to great negative effects regarding the cultivation of tobacco. Therefore, it is imperative to develop efficient technologies to deal with tobacco wastes and utilize tobacco leaves. Nowadays, wastes are often considered as potential resources. Replacing waste disposal with resource recovery is a green method for saving energy [8]. Microbiologists have been engaged in research regarding various applications of tobacco and its wastes because of their high nicotine content, for example, the biotransformation of nicotine into its valuable intermediates, the functionalized pyridines, using nicotine-degrading microorganisms [9-14]. Agrobacterium tumefaciens S33, previously isolated from the tobacco rhizosphere, has a strong ability to degrade nicotine via a hybrid of the pyridine and pyrrolidine pathways (Fig. 1a)
$[4,11]$. It is interesting that at least three intermediates (6-hydroxynicotine, 6-hydroxy-3-succinoylpyridine [HSP], and 2,5-dihydroxypyridine) in this pathway can be used as renewable precursors to synthesize drugs and insecticides via chemical methods. This is due to the hydroxylation of pyridines at the 6-position or 2- and 5 -positions, which can be modified easily via specific and efficient biocatalytic processes [10]. 6-Hydroxynicotine and HSP can be used as valuable precursors to synthesize biologically active 2,5- or 3,5-substituted pyridines, such as the insecticide imidacloprid, the anti-Parkinson's agent SIB-1508Y, and analogs of the potent analgesic Epibatidine, which has obvious paregoric effects $[9,10,15]$. Furthermore, 6-hydroxynicotine and some derivatives perform functions for memory enhancement and oxidation resistance [16], transgene expression induction [17], and microbial resistance $[18,19]$. Consequently, using nicotine to produce valuable compounds through a combination of biocatalysis and chemocatalysis offers the possibility for developing new applications for tobacco and its wastes.

Biocatalysis with microbial whole cells is a promising process for industrial production $[10,20]$. Compared with chemical methods, biocatalysis is safer, more specific, more sustainable, and more environmentally friendly. The reaction conditions are also less stringent. Compared with the use of enzymes as biocatalysts, whole cells can be repetitively and economically utilized, and their cofactor regeneration is much easier and less expensive [10].

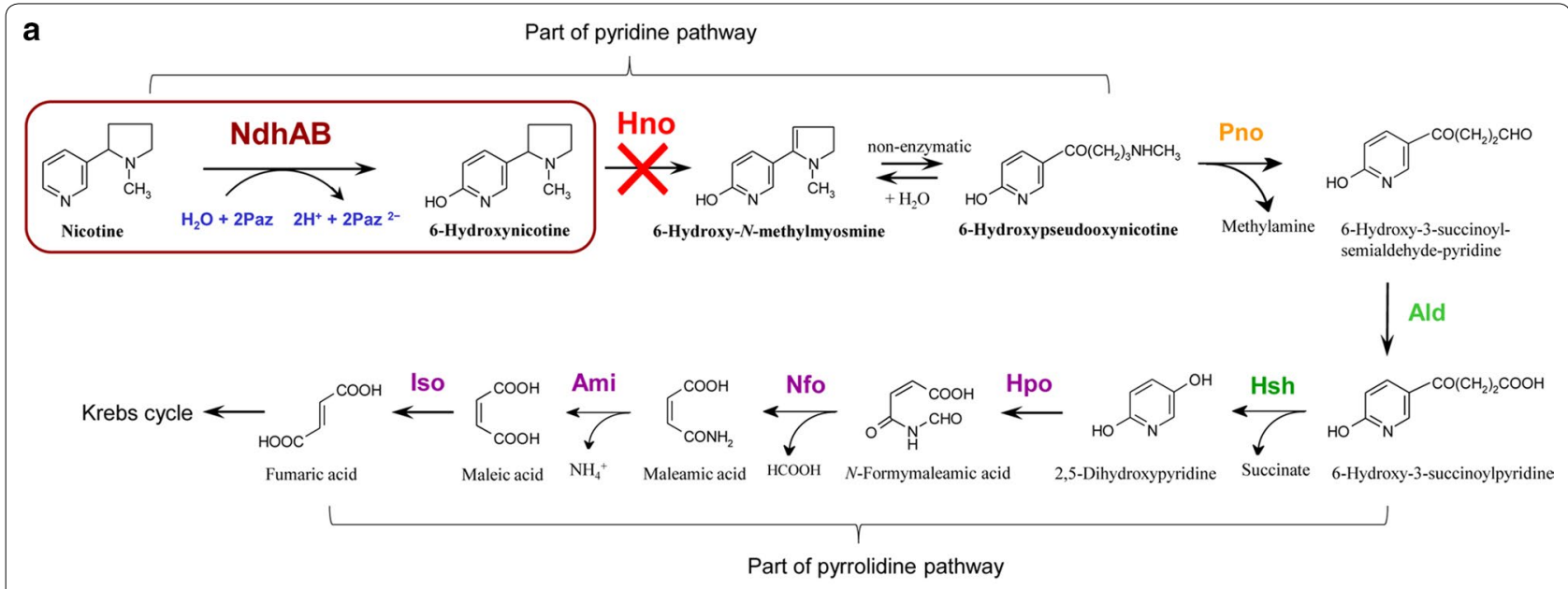

b

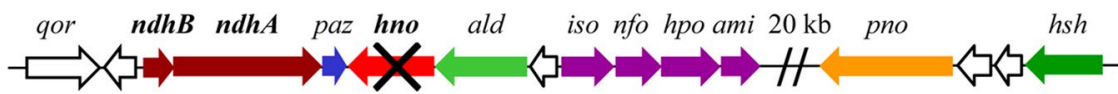

Fig. 1 The hybrid pathway for nicotine degradation in A. tumefaciens S33 (a) and its nicotine-degrading gene cluster (b). NdhAB, nicotine dehydrogenase; Paz, pseudoazurin; Hno, 6-hydroxynicotine oxidase; Pno, 6-hydroxypseudooxynicotine oxidase; Ald, putative aldehyde dehydrogenase; Hsh, 6-hydroxy-3-succinoylpyridine hydroxylase; Hpo, 2,5-dihydroxypyridine dioxygenase; Nfo, $\mathrm{N}$-formylmaleamate deformylase; Ami, maleamate amidohydrolase (amidase); Iso, maleate cis/trans-isomerase. The red cross in panel a indicates that the pathway has been blocked by disabling the enzyme Hno; the black cross in panel $\mathbf{b}$ shows our strategy of disrupting the hno gene 
As a result, biocatalysis based on whole cells provides a continuous process for environmentally friendly energy recovery. However, throughout the whole-cell reaction process, the valuable intermediates of nicotine degradation continue to be further catabolized by the wild-type strains cells $[9,12,19]$, leading to a low molar conversion and the formation of by-products that cause difficulties for product purification. For this reason, greater efforts are required for the optimization of biocatalyst preparation and catalytic conditions. Recently, great interest has been aroused regarding the development of novel biocatalytic processes to achieve high efficiency and selectivity. Thus, engineered bacteria have been suggested as a potential solution, presenting a new approach for the use and control of microbial transformations [21, 22]. By deleting one or several genes required for catabolism, the nicotine degradation pathway is blocked, and the accumulation of valuable intermediates is achieved $[13,14]$.

Herein, the efforts were put forth to test the transformation of nicotine into 6-hydroxynicotine by $A$. tumefaciens S33, knowing that this strain harbors nicotine dehydrogenase (NdhAB) that can catalyze nicotine hydroxylation at the 6-position of the pyridine ring with pseudoazurin as its electron acceptor (Fig. 1a) [23, 24]. First, we purified and characterized the key enzyme 6-hydroxynicotine oxidase (Hno) that catalyze the oxidation of 6-hydroxynicotine to 6-hydroxy- $\mathrm{N}$-methylmyosmine in A. tumefaciens S33. Then, the hno gene of strain S33 was disrupted, causing the degradation of nicotine to be blocked at 6-hydroxynicotine (Fig. 1b). After optimizing the reaction conditions and the biocatalyst preparation conditions, we developed a novel and efficient green route for producing 6-hydroxynicotine with the whole cells of the engineered hno-disrupted strain S33 as the catalyst.

\section{Results and discussion}

\section{Purification of Hno from A. tumefaciens $\mathrm{S} 33$} and identification of its encoding gene

In our previous study on purification of $\mathrm{Ndh} A B$, three yellow-colored fractions adjacent to the NdhAB-containing fractions were found to have 6-hydroxynicotine oxidation activity after separation by DEAE Fast Flow column [24]. The protein was further purified by applying to Q Sepharose and eluted with $0.25 \mathrm{M} \mathrm{NaCl}$, which was nearly pure, as detected by SDS-PAGE (Fig. 2a), and presented a specific 6-hydroxynicotine oxidation activity of $12.0 \pm 1.4 \mu \mathrm{mol} \mathrm{min}{ }^{-1} \mathrm{mg}^{-1}$. To identify its encoding genes, the purified protein was analyzed using MALDI-TOF/MS. The MS results were searched against the annotated genome of A. tumefaciens S33 $[25,26]$. We found that the enzyme was encoded by an ORF of $1314 \mathrm{bp}$, designated as hno, which formed one large gene cluster together with the genes for $\mathrm{NdhAB}$, Pno, and Hsh (Fig. 1b); however, its transcription direction was opposite to $n d h A B$. The identification of the hno gene was supported also by our previous transcriptomic analysis, where a $\log _{2}$ ratio (FPKM of Nic/FPKM of Glu) (FPKM, fragments per kilobase per million) of 5.9 for the hno gene was observed in nicotine medium (Nic) and glucose-ammonium medium (Glu) [25]. The deduced protein sequence (437 amino acids, $48.76 \mathrm{kDa}$ ) has $99.8 \%$ identity to both 6-hydroxynicotine oxidase NctB from Shinella sp. HZN7 [27] and 6-hydroxynicotine oxidase VppB from Ochrobactrum sp. SJY1 [28], 38.9\% to nicotine oxidase Nox from Pseudomonas sp. HZN6 [29], $38.4 \%$ to nicotine oxidoreductase NicA2 from $P$. putida S16 [30], and 24.8\% to 6-hydroxy-L-nicotine oxidase from A. nicotinovorans [31,32]. All these proteins harbor a conserved FAD-binding motif, suggesting that Hno in strain S33 is also a flavin-containing oxidoreductase.

\section{Heterologous production and properties of recombinant Hno}

In order to confirm the function of the hno gene, we heterologously expressed it in E. coli BL21 (DE3) with a His tag at the $\mathrm{N}$-terminus and purified the recombinant protein using His Trap HP and DEAE Sepharose Fast Flow columns (Fig. 2b). A single band with an apparent molecular mass of $50 \mathrm{kDa}$ was detected by SDS-PAGE, which was identical to the calculated molecular mass of the His-tagged Hno and wild-type Hno purified from A. tumefaciens S33 (Fig. 2a). HPLC analysis showed that the yellow protein contained a FAD, which was consistent with the fact that the protein harbors a Rossmannlike domain, as shown by conserved domain analysis in NCBI, and exhibited a typical absorption of flavin at 382 and $459 \mathrm{~nm}$ (Fig. 2C). Enzyme assays showed that at $37^{\circ} \mathrm{C}$ and $\mathrm{pH} 9.2$ (100 mM Glycine-NaOH buffer), the enzyme showed a $V_{\max }$ of $26.43 \pm 0.16 \mathrm{U} / \mathrm{mg}$, and an apparent $K_{m}$ for 6-hydroxynicotine of $0.067 \pm 0.001 \mathrm{mM}$ (Fig. 2d), which are both similar to the kinetic constants of NctB and VppB from Shinella sp. HZN7 [27] and Ochrobactrum sp. SJY1 [28], respectively.

The reaction products catalyzed by the purified Hno were analyzed by UV-visible spectrophotometer. The absorption spectra (Fig. 2e) showed that the absorption of the substrate 6-hydroxynicotine (maximum absorption at $295 \mathrm{~nm}$ ) decreased and a new peak appeared (maximum absorption at $334 \mathrm{~nm}$ ), indicating that 6-hydroxynicotine was transformed into other compounds. The products were further analyzed by LC-MS (Fig. 3). Three large peaks were found in the chromatography (retention time as 4.90, 5.31, and $6.67 \mathrm{~min}$, respectively) (Fig. 3), and monitored with a photodiode array (PDA) detector. The mass-to-charge ratios $(\mathrm{m} / \mathrm{z})$ of the main fragments 

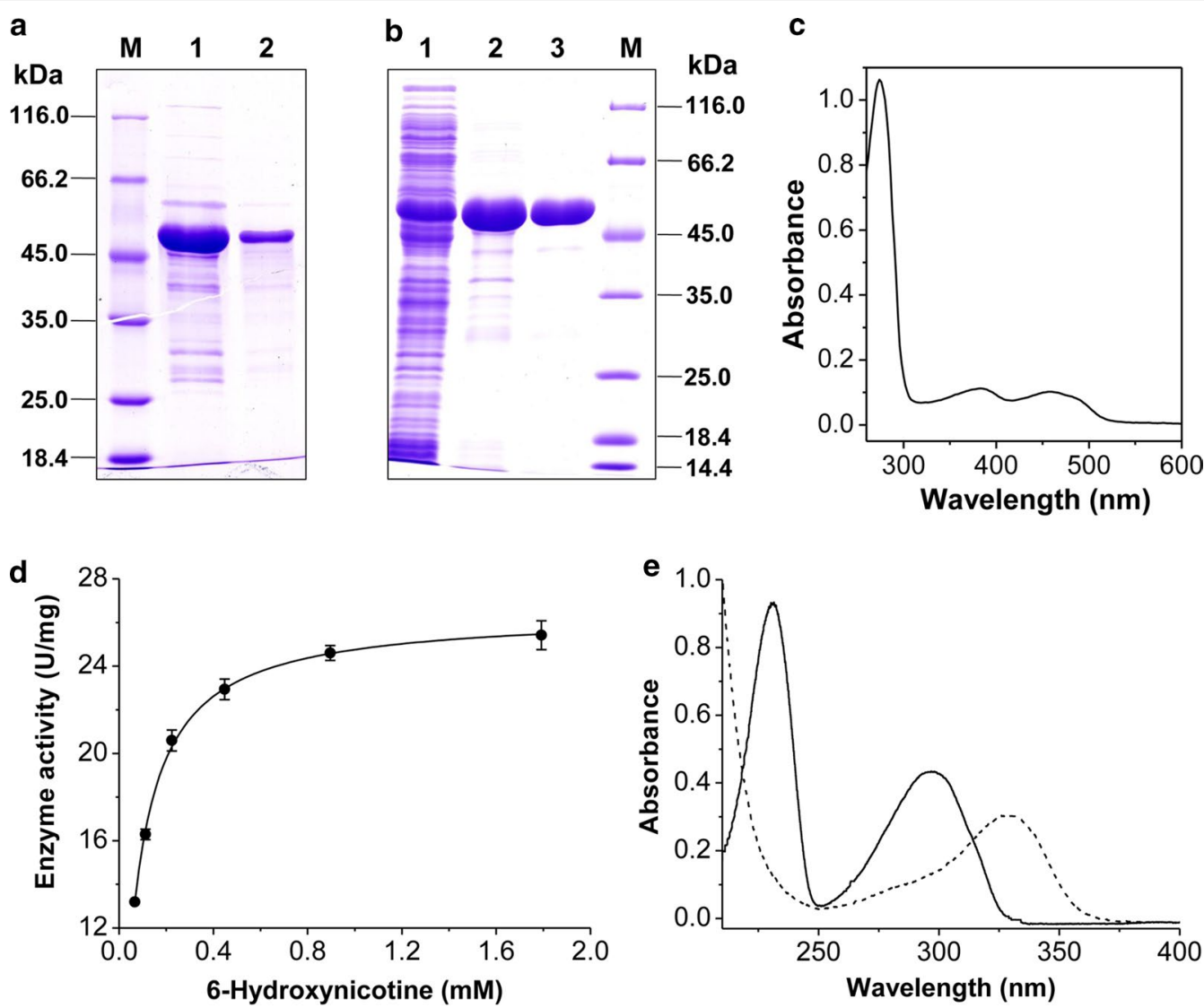

Fig. 2 Purification and properties of the Hno from A. tumefaciens S33. a The wild-type Hno purified from A. tumefaciens S33. M, markers; 1, DEAE Sepharose Fast Flow; lane 2, Q Sepharose. b The recombinant His-tagged Hno. Lane 1, cell extracts of the recombinant E. coli BL21 (DE3); lane 2, His Trap HP; lane 3, DEAE Sepharose Fast Flow; M, markers. c UV-visible absorption spectrum of $0.6 \mathrm{mg} \mathrm{mL}^{-1}$ purified recombinant His-tagged Hno in $50 \mathrm{mM}$ sodium phosphate buffer ( $\mathrm{pH}$ 7.0). d Determination of the kinetic constants from the 6-hydroxynicotine oxidation. e UV-visible absorption spectra of the substrate 6-hydroxynicotine (solid line) and the products of 6-hydroxynicotine oxidation catalyzed by purified recombinant Hno (dashed line)

in the mass spectra are identical to the calculated molecular mass of 6-hydroxynicotine (peak a, $\mathrm{m} / \mathrm{z} 179.1$ ), 6-hydroxy- $N$-methylmyosmine (peak $\mathrm{b}, m / z$ 177.1), and 6-hydroxypseudooxynicotine (peak c, $m / z$ 195.1). This indicates that Hno transforms 6-hydroxynicotine into the 6-hydroxy- $N$-methylmyosmine, which then is converted spontaneously into 6-hydroxypseudooxynicotine, just like the reaction catalyzed by 6 -hydroxy-L-nicotine oxidase in the pyridine pathway of $A$. nicotinovorans [33]. These results confirm that Hno from strain S33 is a FADcontaining oxidase and that it catalyzes the second step of 6-hydroxynicotine oxidation in the hybrid nicotine degradation pathway.

\section{Construction of the strain with disrupted $h n o$ gene and its complementation strain}

To block the 6-hydroxynicotine oxidization by Hno in the nicotine-degrading pathway of strain S33, we disrupted the hno gene with the plasmid PJQ200SK harboring the truncated target gene and then complemented with the plasmid pBBR1MCS-5 containing a complete copy of hno. Growth tests showed that the mutant strain S33- $\Delta$ hno could grow well in lysogeny broth (LB) (Fig. 4a) and HSP media (Fig. 4b) but not in nicotine (Fig. 4c) or 6-hydroxynicotine media (Fig. 4d), while the wild-type strain and the complemented strain S33- $\Delta h n o-C$ could grow in all media. The results confirm that the $h n o$ gene is responsible for the oxidation of 6-hydroxynicotine and is required for nicotine degradation in strain S33. The mutant strain S33- $\Delta$ hno lost the ability to further catabolize 6-hydroxynicotine.

The activities of NdhAB and Hno in all strains were measured when they were grown in HSP medium or nicotine-glucose-ammonium medium (Table 1). The results showed that Hno activity was not detected in the mutant strain S33- $\Delta h n o$. Interestingly, when strain S33$\Delta h n o$ was cultured in HSP medium, its Ndh activity was much higher than when cultured in nicotine-glucoseammonium medium. 

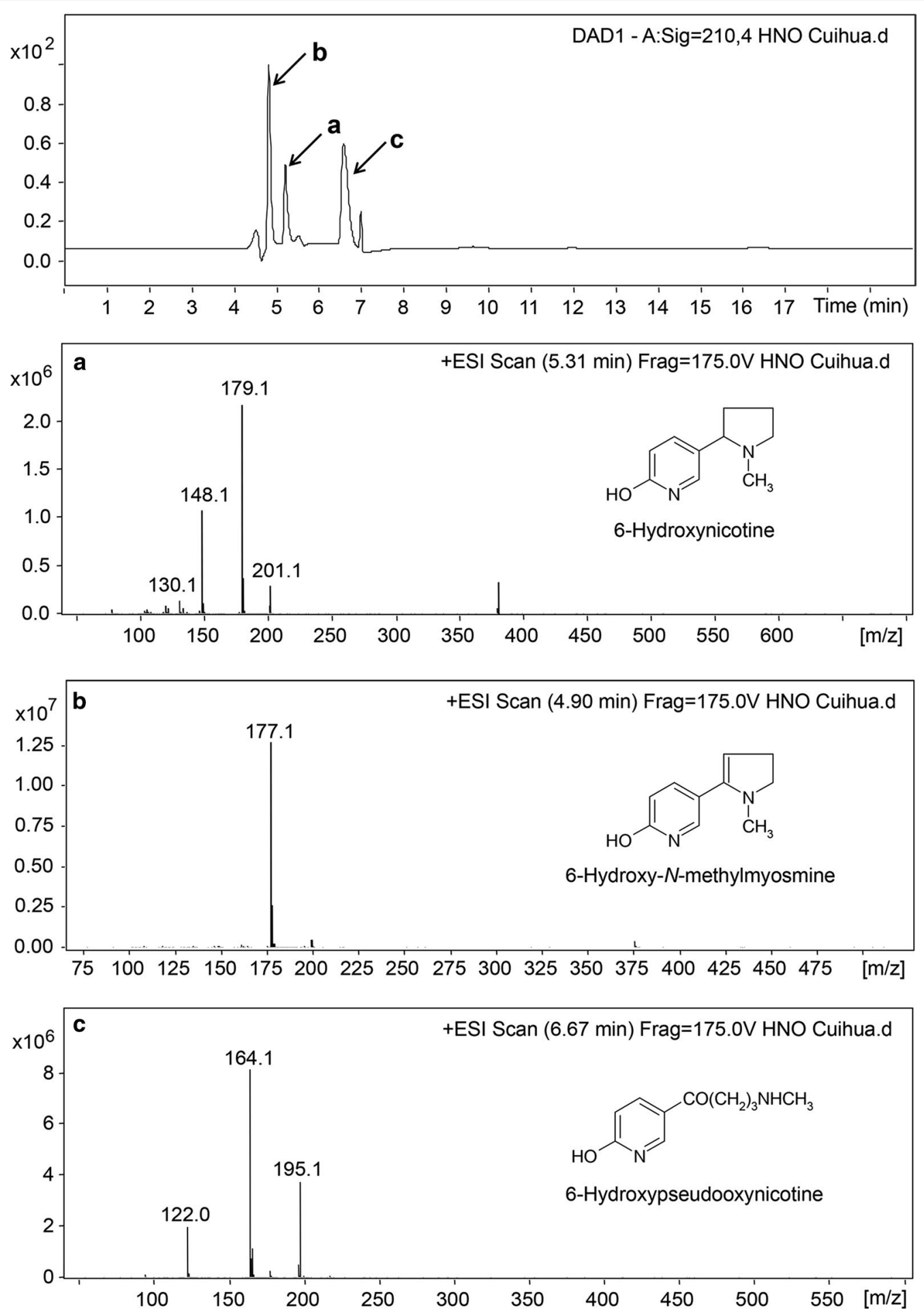

Fig. 3 LC-MS profiles of the reaction catalyzed by recombinant Hno from A. tumefaciens S33. The HPLC profile was obtained by monitoring with a PDA detector at $210 \mathrm{~nm}$; a-c the mass spectra of the substrate 6-hydroxynicotine $(\mathrm{m} / \mathrm{z} 179.1)$ and the products 6-hydroxy- $\mathrm{N}$-methylmyosmine $(\mathrm{m} / \mathrm{z}$ 177.1) and 6-hydroxypseudooxynicotine ( $\mathrm{m} / \mathrm{z}$ 195.1), respectively. Positively charged ions were detected 

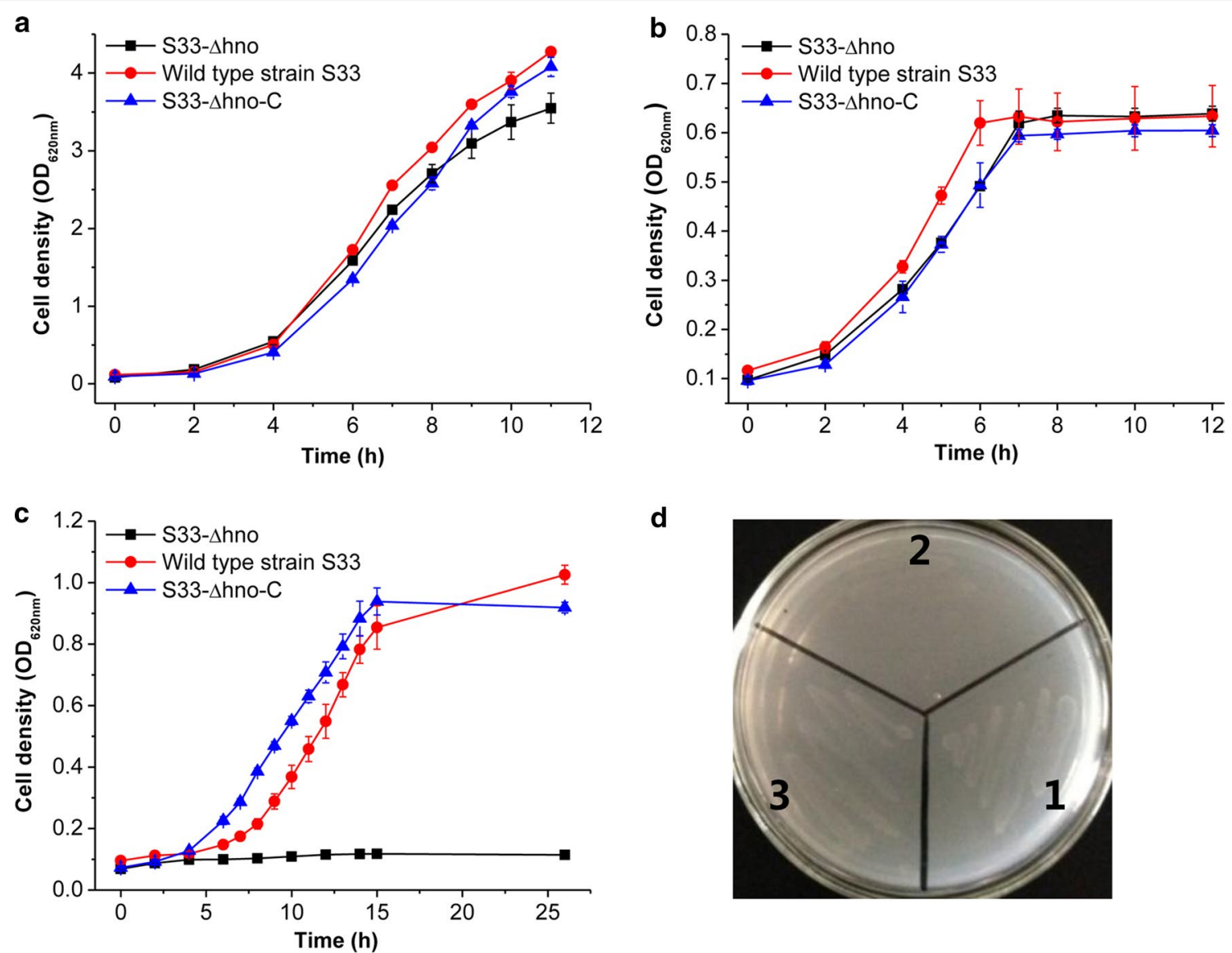

d

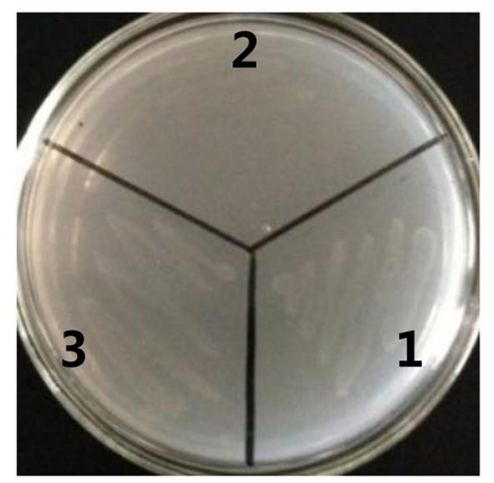

Fig. 4 Growth of wild-type A. tumefaciens S33, A. tumefaciens S33- $\triangle$ hno, and A. tumefaciens S33- $\Delta$ hno-C in LB (a), HSP (b), nicotine (c), and 6-hydroxynicotine (d) media. In panel d: 1, wild-type strain S33; 2, strain S33- $\Delta h n o ; 3$, strain S33- $\Delta h n o-C$

Table 1 The NdhAB and Hno activity of wild-type A. tumefaciens S33, A. tumefaciens S33- $\Delta$ hno, and A. tumefaciens S33$\Delta h n o-C$ cultured in HSP medium (a) or nicotine-glucose-ammonium medium (b)

\begin{tabular}{|c|c|c|c|c|c|c|}
\hline \multirow[t]{2}{*}{ Enzyme } & \multicolumn{3}{|l|}{ Sp act (U/mg)-a } & \multicolumn{3}{|l|}{ Sp act (U/mg)-b } \\
\hline & Wild-type S33 & S33- $\Delta h n o$ & S33- $\Delta h n o-C$ & Wild-type S33 & S33- $\Delta h n o$ & S33- $\Delta$ hno-C \\
\hline NdhAB & $0.47 \pm 0.019$ & $0.53 \pm 0.021$ & $0.52 \pm 0.025$ & $0.42 \pm 0.018$ & $0.03 \pm 0.005$ & $0.14 \pm 0.013$ \\
\hline Hno & $0.05 \pm 0.008$ & $<0.001$ & $0.01 \pm 0.002$ & $0.07 \pm 0.010$ & $<0.001$ & $0.03 \pm 0.007$ \\
\hline
\end{tabular}

Testing the biotransformation of nicotine into 6-hydroxynicotine catalyzed by whole cells of $A$. tumefaciens S33- $\Delta$ hno

To determine the possibility of 6-hydroxynicotine production from nicotine, the biotransformation reaction was performed using whole cells of $A$. tumefaciens S33- 4 hno ( $1.45 \mathrm{~g} \mathrm{~L}^{-1}$, dry cell weight, DCW; 3.6 $\mathrm{OD}_{620 \mathrm{~nm}}$; one OD unit $=0.41 \mathrm{~g} \mathrm{~L}^{-1} \mathrm{DCW}$ ) as a catalyst and $0.85 \mathrm{~g} \mathrm{~L}^{-1}$ nicotine as the substrate in $50 \mathrm{mM}$ sodium phosphate buffer ( $\mathrm{pH}$ 7.0). The cells were cultured with nicotine-glucose-ammonium medium in consideration of the high cost of HSP, where nicotine could induce the expression of the $n d h A B$ gene according to the results in Table 1 and previous investigations [24, 25]. The mixture was shaken at $30{ }^{\circ} \mathrm{C}$ with a speed of $200 \mathrm{rev} \mathrm{min}^{-1}(\mathrm{rpm})$. Samples were withdrawn and analyzed by HPLC to monitor the consumption of the substrate and the formation of the product. Results showed a significant increasing peak with retention time at $5.2 \mathrm{~min}$ and a decreasing peak with retention time at $6.0 \mathrm{~min}$ (Fig. 5a), which correspond to 6-hydroxynicotine and nicotine, respectively. Finally, nicotine can be converted completely into 

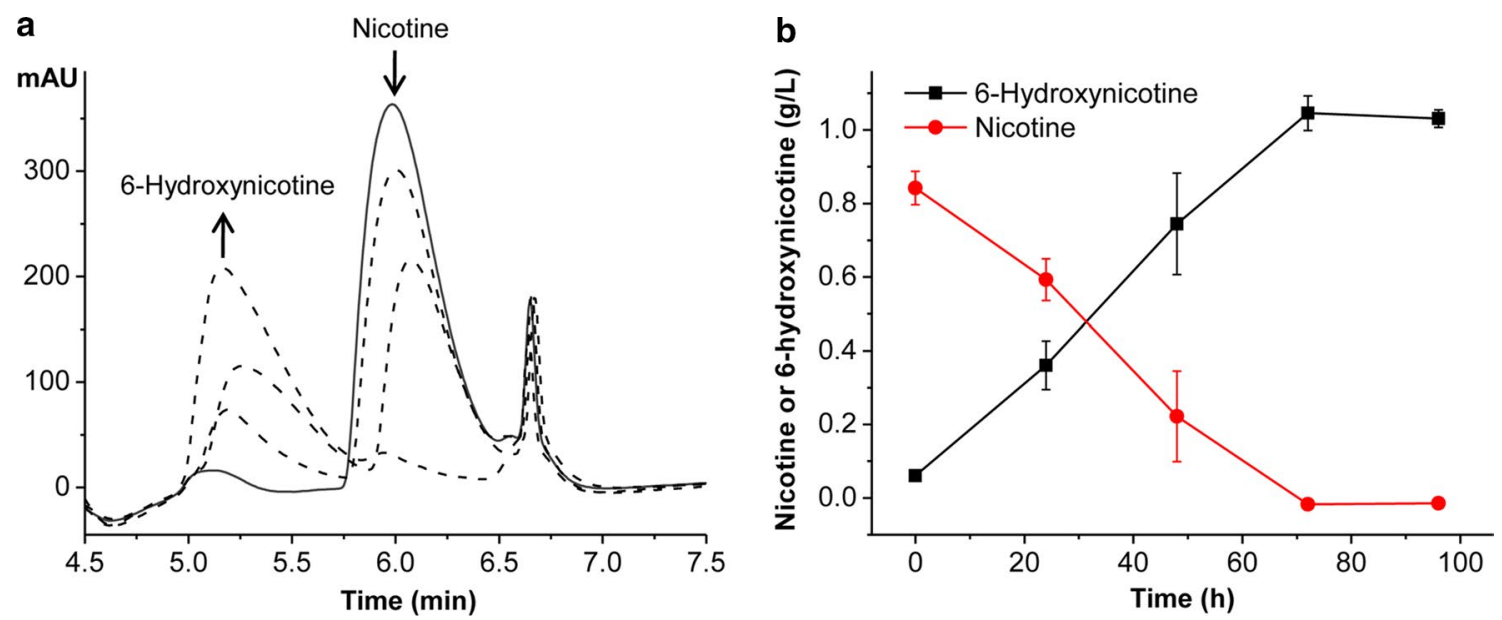

Fig. 5 Biotransformation of nicotine into 6-hydroxynicotine catalyzed by the whole cells of A. tumefaciens S33- $\Delta h n$. a HPLC profile of the reaction mixtures sampled at different time after starting the reaction. The increase and decrease of the peaks during the reaction are indicated by upward or downward arrows, respectively. $\mathbf{b}$ Time course of the biotransformation reaction

6-hydroxynicotine (Fig. 5b). However, the specific catalytic activity of $\sim 0.01 \mathrm{~g}$ 6-hydroxynicotine $\mathrm{h}^{-1} \mathrm{~g}^{-1}$ dry cells was very low, which needs to be improved.

\section{Optimization of the reaction conditions for the} biotransformation of nicotine into 6-hydroxynicotine

To improve the catalytic rate, reaction conditions were optimized. As shown in Fig. 6, the catalytic rate was affected by the amount of $A$. tumefaciens S33- $\Delta$ hno whole cells added, the initial concentration of nicotine, $\mathrm{pH}$ of the buffer, and the incubation temperature. The catalytic rate rose remarkably with the increasing dry weight of the catalyst (Fig. 6a) and the decreasing initial concentration of nicotine (Fig. 6b); however, the specific catalytic rate did not continue to increase when above $2.7 \mathrm{~g} \mathrm{~L}^{-1}$ of biocatalyst was added (Fig. 6a). The high concentration of nicotine inhibited the catalytic activity. The optimal $\mathrm{pH}$ and temperature for the reaction was around 7.0 (Fig. 6c) and $30^{\circ} \mathrm{C}$ (Fig. $6 \mathrm{~d}$ ), respectively, which was in consistent with the optimal growth conditions for A. tumefaciens S33 [4]. Figure 6e shows that oxygen was essential for the reaction although the key enzyme catalyzing nicotine hydroxylation is a pseudoazurin-dependent NdhAB [23]. We speculate that oxygen is the final electron acceptor of nicotine oxidative degradation, which accepts the electron from the reduced pseudoazurin via the respiratory chain. Thus, the pseudoazurin can be regenerated in the biotransformation reaction. For the tested system, a low rotation rate supplied enough oxygen to the reaction (Fig. 6e). Finally, the preparation of the whole-cell biocatalyst was examined. Different media were used for culturing A. tumefaciens S33- $\Delta$ hno (Fig. 6f), where nicotine or HSP was used as an inducer for expressing the nicotine-degrading enzymes, including $\mathrm{NdhAB}[24,25]$. The results showed that the cells grown in the media containing HSP presented higher catalytic efficiency, which was even better than those grown on nicotine, while LB was the worst medium for preparing the biocatalyst. This agreed with the results from the enzyme assay for the cell extracts of $A$. tumefaciens S33- $\Delta$ hno (Table 1), where HSP demonstrated a better induction for NdhAB activity. In consideration of the cost of HSP and biomass obtained, we chose the glucose-ammonium-HSP medium to culture A. tumefaciens S33- $\Delta$ hno.

\section{Batch and fed-batch biotransformation reactions}

Under the optimal conditions $\left(\mathrm{pH} 7.0\right.$ and $\left.30{ }^{\circ} \mathrm{C}\right)$, we performed the reaction in $200 \mathrm{~mL}$ reaction mixture containing $1 \mathrm{~g} \mathrm{~L}^{-1}$ nicotine and $\sim 1.0 \mathrm{~g} \mathrm{~L}^{-1} \mathrm{DCW}$ whole cells of A. tumefaciens S33- $\Delta$ hno cultured with glucose-ammonium-HSP medium. For batch biotransformations, the catalyst was collected by centrifugation after the first batch reaction and was re-used for three subsequent reactions. As shown in Fig. 7a, the wholecell biocatalyst could maintain high activity even after being used in four separate reactions. The highest specific catalytic activity reached approximately $1.01 \mathrm{~g}$ 6-hydroxynicotine $\mathrm{h}^{-1} \mathrm{~g}^{-1}$ dry cells. For each batch, the molar conversion reached $\sim 95 \%$. Due to the inhibitory nature of nicotine (Fig. 6a), we also performed a fed-batch biotransformation (Fig. 7b). During the reaction, we supplemented $1 \mathrm{~g} \mathrm{~L}^{-1}$ of nicotine three times. In total, $4 \mathrm{~g} \mathrm{~L}^{-1}$ of nicotine could be transformed completely into $4.70 \mathrm{~g} \mathrm{~L}^{-1}$ of 6-hydroxynicotine (Fig. 7b). The molar conversion reached $\sim 98.4 \%$. However, the catalytic rate gradually decreased as time increased in 

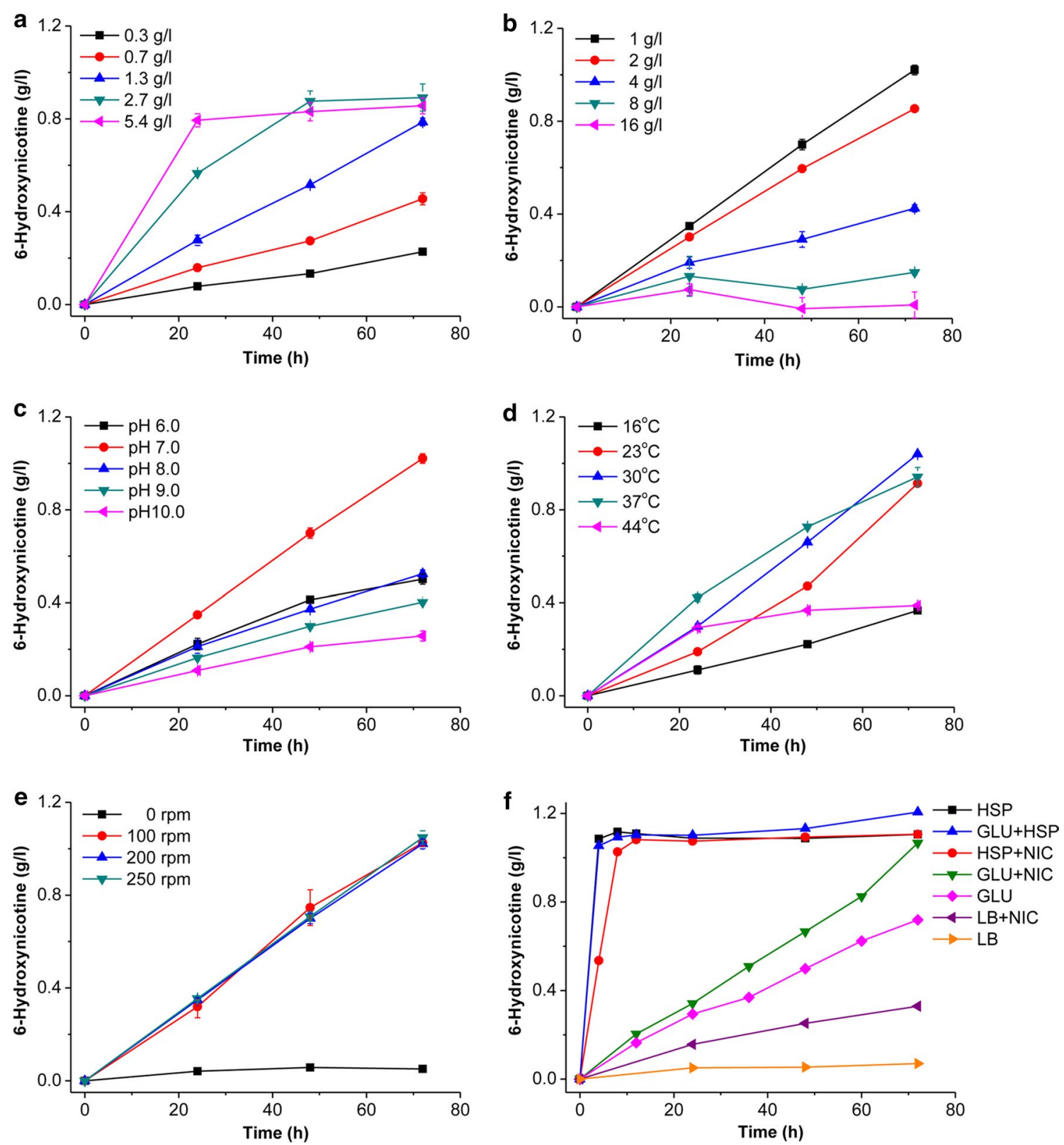

Fig. 6 Optimization of biotransformation conditions to produce 6-hydroxynicotine. Effects of the amount of the catalyst added (dry cell weight, $\mathrm{DCW})(\mathbf{a})$, the initial concentration of nicotine $(\mathbf{b}), \mathrm{pH}(\mathbf{c})$, temperature $(\mathbf{d})$, rotation speed $(\mathbf{e})$, and the media used for preparation of the biocatalyst (f). In panel c: $50 \mathrm{mM}$ sodium phosphate buffer (pH 6.0 and pH 7.0), $50 \mathrm{mM}$ Tris-HCl buffer (pH 8.0), and $50 \mathrm{mM}$ glycine-NaOH buffer (pH 9.0 and pH 10.0) were used. In panel f: HSP, HSP medium; GLU + HSP, glucose-ammonium-HSP medium; HSP + NIC, HSP-nicotine medium; GLU + NIC, glucose-ammonium-nicotine medium; GLU, glucose-ammonium medium; LB + NIC, LB-nicotine medium; LB, lysogeny broth. The reactions were carried out at $30^{\circ} \mathrm{C}$ in $50 \mathrm{mM}$ sodium phosphate buffer ( $\mathrm{pH} \mathrm{7.0)}$ ) with $1.0 \mathrm{~g} \mathrm{~L}^{-1}$ nicotine as the substrate and $\sim 1.5 \mathrm{~g} \mathrm{~L}^{-1}$ DCW whole cells of $A$. tumefaciens S33- $\Delta h n$, or as indicated

both batch and fed-batch reactions, which may be due to poor stability of the NdhAB activity in the cells, as previously indicated $[23,24]$. These results suggest that a combination of fed-batch reactions and recycled biocatalyst reactions would be feasible and ideal for a large scale biotransformation process. Compared with the growing system developed for producing 6-hydroxynicotine from nicotine by wild-type strain Arthrobacter oxydans [9], the catalytic process developed in this study presented both higher conversion rates and higher yields. Moreover, the whole cells biocatalysts could be recovered easily by centrifugation and repeatedly used 


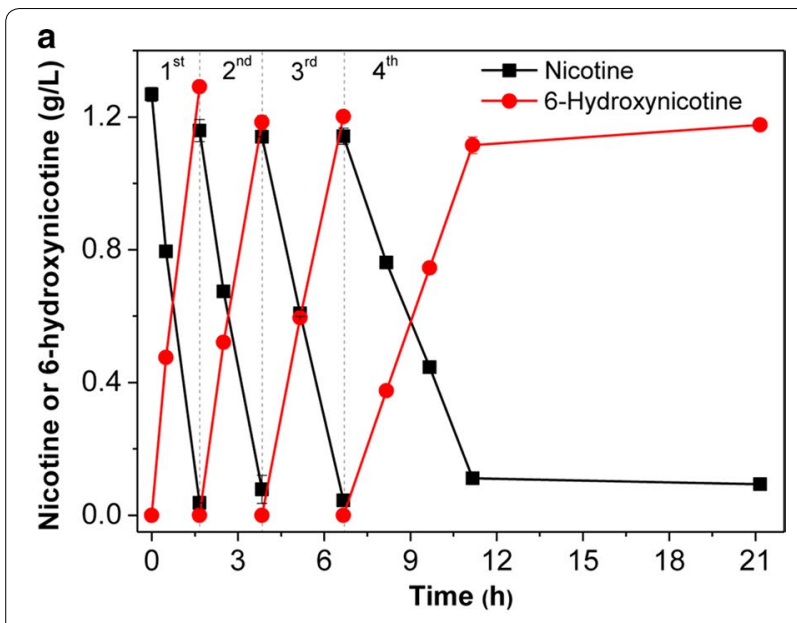

b

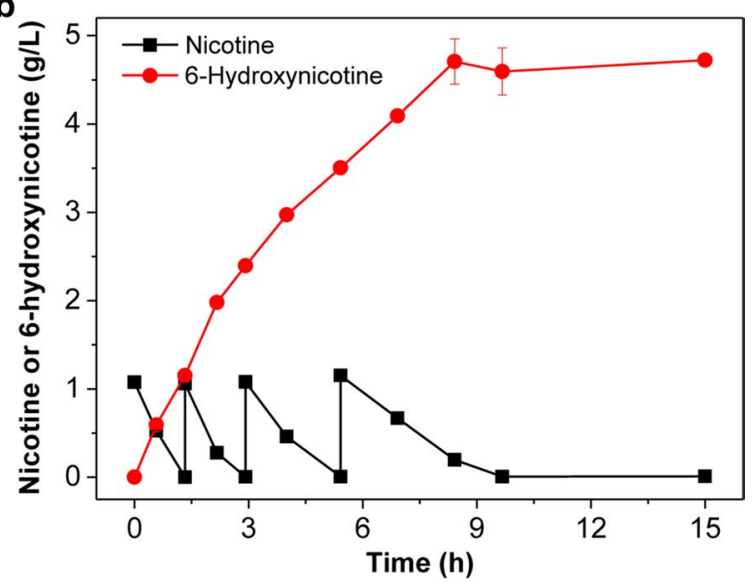

Fig. 7 Batch and fed-batch biotransformation reactions converting nicotine into 6-hydroxynicotine under the optimal conditions. a Time course of the batch biotransformation reactions. The whole cells were re-used three times after the initial reaction. $\mathbf{b}$ Time course of the fed-batch biotransformation reaction. Nicotine was supplemented three times

several times, which is helpful for reducing costs and for product purification.

\section{Purification and identification of the product 6-hydroxynicotine}

The product 6-hydroxynicotine in the reaction mixture was extracted easily by dichloromethane after removing the cells in the reaction mixture by centrifugation and concentrating the supernatant by rotary evaporation under reduced pressure. Finally, $1.20 \mathrm{~g}$ of 6 -hydroxynicotine was recovered from $600 \mathrm{~mL}$ of reaction mixture containing $2.6 \mathrm{~g} \mathrm{~L}^{-1}$ of 6-hydroxynicotine (76.9\% recovery), where a total of approximately $1.43 \mathrm{~g}$ of nicotine was added during the reaction (overall yield, 83.9\%, $\mathrm{w} / \mathrm{w})$. The purified product showed two characteristic maximum absorption peaks, at 232 and $295 \mathrm{~nm}$, in $0.1 \mathrm{M}$
$\mathrm{HCl}$ as indicated by UV-visible absorption spectrum (Fig. 8a), which corresponds to a previous report [34], as well as to authentic 6-hydroxynicotine (Fig. 2e). LCMS determination showed a peak with $\mathrm{m} / z$ as 179.1198 $\left([\mathrm{M}+\mathrm{H}]^{+}\right)$that was identical to the calculated molecular mass of 6-hydroxynicotine $\left(\mathrm{C}_{10} \mathrm{H}_{14} \mathrm{~N}_{2} \mathrm{O}, 178.1106\right.$; Fig. 8b, c). The purified product had an ${ }^{1} \mathrm{H}-\mathrm{NMR}$ spectrum $\left(\mathrm{CDCl}_{3}, 600 \mathrm{MHz}\right)$ as follows: $\delta 1.70(\mathrm{~m}, 1 \mathrm{H}) ; 1.80$ (m, $1 \mathrm{H}) ; 1.92(\mathrm{~m}, 1 \mathrm{H}) ; 2.11(\mathrm{~m}, 1 \mathrm{H}) ; 2.14(\mathrm{~s}, 3 \mathrm{H}) ; 2.27$ (q, $J=9.2 \mathrm{~Hz}, 1 \mathrm{H}) ; 2.85(\mathrm{t}, J=8.3 \mathrm{~Hz}, 1 \mathrm{H}) ; 3.19(\mathrm{td}, J=8.6$, $1.8 \mathrm{~Hz}, 1 \mathrm{H}) ; 6.60(\mathrm{~d}, J=9.4 \mathrm{~Hz}, 1 \mathrm{H}) ; 7.27(\mathrm{~d}, J=2.4 \mathrm{~Hz}$, $1 \mathrm{H}) ; 7.56(\mathrm{dd}, J=9.4,2.5 \mathrm{~Hz}, 1 \mathrm{H}) ;$ a ${ }^{13} \mathrm{C}$-NMR spectrum $\left(\mathrm{CDCl}_{3}, 150 \mathrm{MHz}\right): \delta 22.3\left(\mathrm{CH}_{2}\right), 33.7\left(\mathrm{CH}_{2}\right), 40.0\left(\mathrm{CH}_{3}\right)$,

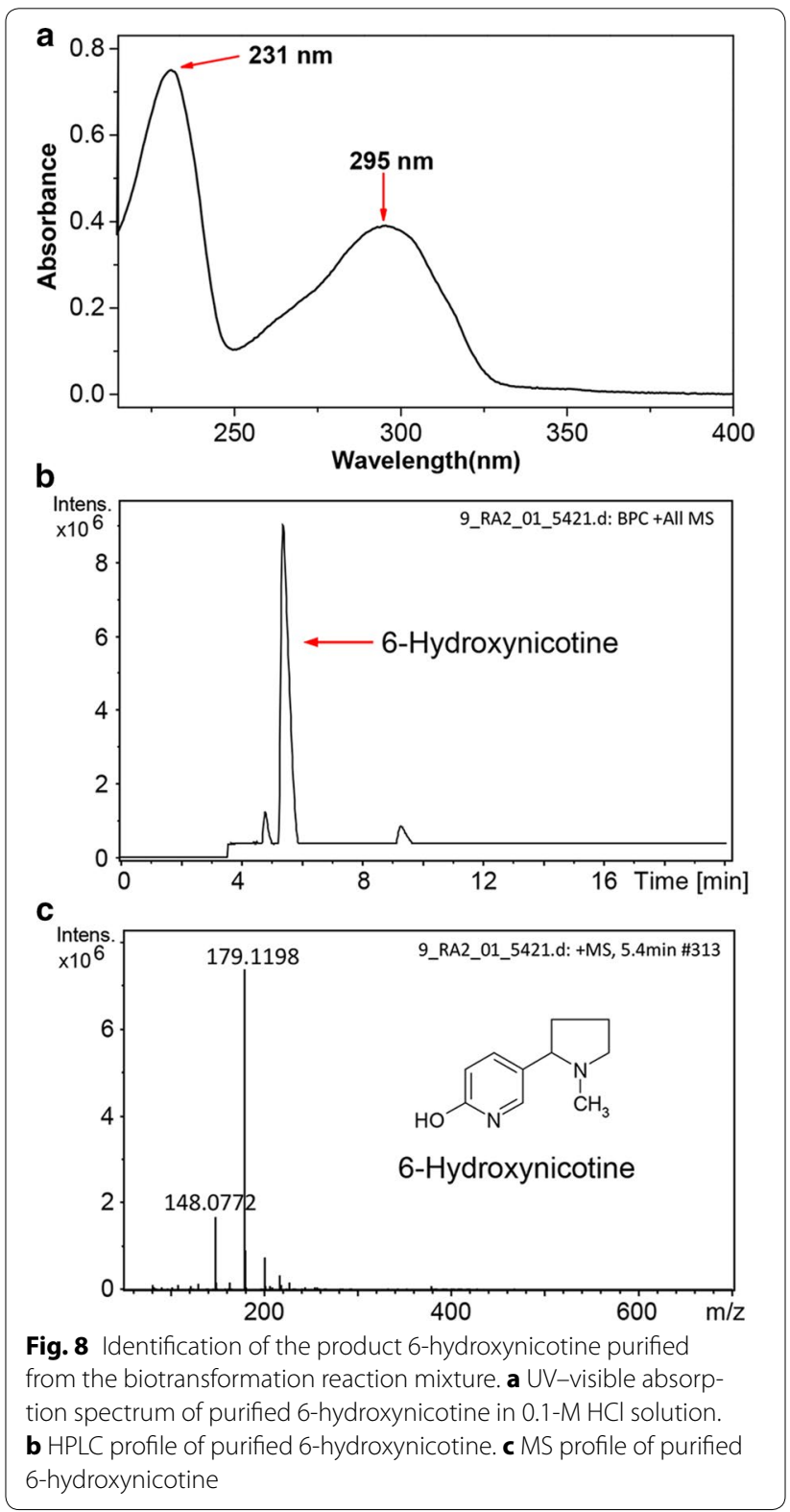


56.6 $\left(\mathrm{CH}_{2}\right), 67.6(\mathrm{CH}), 120.5(\mathrm{C}), 121.6(\mathrm{CH}), 132.7(\mathrm{CH})$, $141.5(\mathrm{CH}), 165.3(\mathrm{C})$ (Additional file 1: Figure S1). The NMR data were consistent with those from the authentic commercial standard 6-hydroxynicotine (Additional file 1: Figure S2) and previous study [9]. These results indicate that the purification of the product 6-hydroxynicotine from the reaction mixture can be achieved practically and easily with a satisfactory yield and purity.

\section{Conclusion}

The disposal and detoxification of nicotine from tobacco and its wastes are a challenge for the tobacco industry. However, this biomass could be used as a potential resource to recover energy. In this study, we transformed nicotine from tobacco and its wastes into the valuable intermediate 6-hydroxynicotine using a nicotine-degrading A. tumefaciens S33 mutant, in which the enzyme $\mathrm{NdhAB}$ catalyzed nicotine hydroxylation with pseudoazurin as its electron acceptor. To accumulate quantities of the intermediate product, we identified the key enzyme Hno, responsible for further oxidative degradation of 6-hydroxynicotine, and disrupted its encoding gene to block the catabolism of 6-hydroxynicotine. With whole cells of the mutant as the biocatalyst, pseudoazurin, the electron acceptor for $\mathrm{NdhAB}$, was regenerated by transferring its electrons to $\mathrm{O}_{2}$ via the respiration chain. At $30{ }^{\circ} \mathrm{C}$ and $\mathrm{pH}$ 7.0, nicotine was nearly completely transformed into 6-hydroxynicotine by the mutant whole cells; the biocatalyst with the highest nicotine transformation activity was obtained by growing the mutant in glucoseammonium-HSP medium. The product was easily purified by dichloromethane extraction. In summary, we developed a novel green route for synthesizing the valuable chemical 6-hydroxynicotine from nicotine and providing an alternative strategy for utilizing tobacco and its wastes.

\section{Methods}

\section{Bacterial strain, plasmids, and culture conditions}

All bacterial strains, vectors, and recombinant plasmids in this study are listed in Table 2. A. tumefaciens S33, deposited at the China center for type culture collection (CCTCC) under accession number CCTCC AB 2016054 (originally CCTCC M 206131), was grown in "nicotine medium" or "nicotine-glucose-ammonium medium" (nicotine medium plus $1.0 \mathrm{~g} \mathrm{~L}^{-1}$ glucose, $0.2 \mathrm{~g} \mathrm{~L}^{-1}$ ammonium sulfate, and $1.0 \mathrm{~g} \mathrm{~L}^{-1}$ yeast extract) at $30{ }^{\circ} \mathrm{C}$, as described previously $[11,35]$. Nicotine was added to the media with a final concentration of $1.0 \mathrm{~g} \mathrm{~L}^{-1}$. 6-Hydroxynicotine medium and HSP medium contain $0.5 \mathrm{~g} \mathrm{~L}^{-1} 6$-hydroxynicotine or HSP instead of nicotine in the nicotine medium, respectively, as the sole sources of carbon and nitrogen. E. coli cells were routinely grown in
Table 2 Strains and plasmids used in this study

\begin{tabular}{|c|c|c|}
\hline Strain or plasmid & Description & Source \\
\hline \multicolumn{3}{|l|}{ Strains } \\
\hline \multicolumn{3}{|l|}{ E. coli } \\
\hline BL21 (DE3) & $\mathrm{F}^{-}$ompThsdS(r $\left.\mathrm{r}_{\mathrm{B}}^{-} \mathrm{m}_{\mathrm{B}}^{-}\right)$gal dcm lacY1(DE3) & Novagen \\
\hline \multicolumn{3}{|l|}{ A. tumefaciens } \\
\hline S33 & Wild-type, nicotine degrader; $\mathrm{G}^{-}$ & [4] \\
\hline S33- $\Delta h n o$ & $\mathrm{Gm}^{\mathrm{r}} ;$ hno mutant of strain S33 & This study \\
\hline S33- $-\Delta h n o-C$ & $\begin{array}{l}\text { Gmr'; strain S33- } \Delta \text { hno containing pBBR- } \\
\quad h n o\end{array}$ & This study \\
\hline \multicolumn{3}{|l|}{ Plasmid } \\
\hline pETDuet-1 & $A p^{r} ;$ expression vector & Novagen \\
\hline pETDuet-1-hno & Ap $;$; pETDuet-1 containing hno gene & This study \\
\hline pJQ200SK & $\begin{array}{l}\mathrm{Gm}^{r} ; \text { mob }^{+} \text {orip } 15 \mathrm{~A} \text {, lacZa } \mathrm{a}^{+} \text {sac B; } \\
\text { suicide plasmid }\end{array}$ & [39] \\
\hline $\mathrm{pJQ}-\Delta h n o$ & $\begin{array}{l}\mathrm{Gm}^{\mathrm{r}} ; \text { hno were disrupted and inserted } \\
\text { into pJQ200SK }\end{array}$ & This study \\
\hline pRK2013 & Km; helper plasmid for conjugation & Clontech \\
\hline pBBR1MCS-5 & $\mathrm{Gm}^{\mathrm{r}}$; broad-host-range cloning vector & {$[40]$} \\
\hline pBBR-hno & $\mathrm{Gm}^{\mathrm{r}} ;$ hno inserted into pBBR1-MCS5 & This study \\
\hline
\end{tabular}

LB medium (10.0 $\mathrm{g} \mathrm{L}^{-1}$ tryptone, $5.0 \mathrm{~g} \mathrm{~L}^{-1}$ yeast extract, and $\left.10.0 \mathrm{~g} \mathrm{~L}^{-1} \mathrm{NaCl}, \mathrm{pH} 7.5\right)$ at $37^{\circ} \mathrm{C}$. Nicotine (> 99\%) was obtained from Fluka (Buchs, Switzerland). HSP was purified from the culture broth of the nicotine-degrading P. putida S16 as described [12]. Authentic 6-hydroxynicotine was bought from Toronto Research Chemicals, Inc. (Toronto, Canada). All other chemicals were commercially available. The antibiotics and concentrations used were as follows: ampicillin (Ap), $100 \mathrm{mg} \mathrm{L}^{-1}$; gentamicin (Gm), $50 \mathrm{mg} \mathrm{L}^{-1}$.

\section{Enzyme assays}

All assays were carried out in quartz cuvettes $(1-\mathrm{cm}$ light path) filled with $1 \mathrm{~mL}$ of reaction mixture at $30^{\circ} \mathrm{C}$ using a UV-visible Ultrospec 2100 pro Spectrophotometer (GE Healthcare, USA). The reactions were initiated by the addition of enzyme. Ndh activity was determined as previously described [11] by monitoring the reduction of 2,6-dichlorophenolindophenolsodium (DCIP) with nicotine at $600 \mathrm{~nm}\left(\varepsilon=21 \mathrm{mM}^{-1} \mathrm{~cm}^{-1}\right)$. The assay mixture contained $1 \mathrm{mM}$ nicotine, $0.05 \mathrm{mM}$ DCIP, and $50 \mathrm{mM}$ phosphate buffer ( $\mathrm{pH} 7.0$ ). Hno activity was measured by detecting the formation of 6-hydroxypseudooxynicotine as previously reported [36]. The assay mixture contained $0.56 \mathrm{mM}$ 6-hydroxynicotine, $100 \mathrm{mM} \mathrm{NaCl}$, and $100 \mathrm{mM}$ glycine- $\mathrm{NaOH}$ buffer ( $\mathrm{pH}$ 9.2). The formation of 6-hydroxypseudooxynicotine was followed at $334 \mathrm{~nm}$ $\left(\varepsilon=20.7 \mathrm{mM}^{-1} \mathrm{~cm}^{-1}\right)$. One unit (U) of enzyme activity was defined as the amount of enzyme catalyzing the conversion $1 \mu \mathrm{mol}$ of substrate per minute. Protein 
concentration was measured using the Bradford assay with bovine serum albumin as the standard [37].

\section{Purification of Hno from A. tumefaciens S33 and identification of its encoding gene}

Cells were grown in nicotine-glucose-ammonium medium and disrupted by sonication according to the procedure for purifying NdhAB [24]. During the purification of NdhAB using DEAE Sepharose Fast Flow (GE Healthcare) [24], three yellow-colored fractions were eluted with $0.25 \mathrm{M} \mathrm{NaCl}$ concentration adjacent to the fractions containing $\mathrm{NdhAB}$ activity and were found to present Hno activity. The fractions with Hno activity were concentrated, desalted with $50 \mathrm{mM}$ phosphate buffer ( $\mathrm{pH}$ 7.0), and applied to a Q Sepharose column (GE Healthcare) equilibrated with $50 \mathrm{mM}$ phosphate buffer ( $\mathrm{pH}$ 7.0). The column was eluted at a $4-\mathrm{mL} \mathrm{min}^{-1}$ flow rate with five column volumes of the same buffer containing $0.1,0.2,0.25,0.4$, and $0.5 \mathrm{M} \mathrm{NaCl}$ as step gradients. Hno activity was eluted with $\mathrm{NaCl}$ of $0.25 \mathrm{M}$. After being concentrated and desalted, the enzyme was analyzed by SDS-PAGE. The purified enzyme was digested with trypsin and analyzed using MALDI-TOF MS analysis as described [24]. The results were searched against the genome of $A$. tumefaciens S33 [26] to identify the potential encoding genes of Hno.

\section{Heterologous expression and purification of Hno}

The hno gene was amplified by PCR using the genomic DNA of strain S33 as the template. PCR primers (hno-F and hno-R, Table 3) were designed to incorporate restriction sites (BamHI/HindIII) for subsequent ligation into an expression vector. The PCR products were then digested by BamHI and HindIII and ligated into the expression vector pETDuet-1, which was then transformed into $E$. coli BL21 (DE3) for expression. The recombinant $E$. coli BL21 (DE3) strains were grown in $\mathrm{LB}$ at $37{ }^{\circ} \mathrm{C}$ to an optical density of $0.4-0.6$ at $620 \mathrm{~nm}$, and the induction was initiated by supplementing with $0.1 \mathrm{mM}$ isopropyl- $\beta$-D-thiogalactopyranoside (IPTG) at $16{ }^{\circ} \mathrm{C}$. After incubation for $12 \mathrm{~h}$, cells were harvested and disrupted by sonication. The His-tagged protein was purified using a $5 \mathrm{~mL}$ HisTrap HP column (GE Healthcare). The target protein was eluted with a linear gradient of imidazole ranging from 50 to $200 \mathrm{mM}$ in $20 \mathrm{mM}$ $\mathrm{NaH}_{2} \mathrm{PO}_{4}$ (pH 7.0) buffer. To remove contaminants, active fractions were further applied to a DEAE Sepharose column that was washed with two column volumes of $50 \mathrm{mM}$ phosphate buffer ( $\mathrm{pH} 7.0$ ) and then eluted with the same buffer containing $0.1,0.2,0.3$, and $0.5 \mathrm{M} \mathrm{NaCl}$ by step gradients (two column volumes per each step). Hno activity was eluted with $0.2 \mathrm{M} \mathrm{NaCl}$. The purity of the protein was detected by SDS-PAGE.
Table 3 Primers for expression, disruption, and complementation of the hno gene

\begin{tabular}{ll}
\hline Primers & Sequence $\left(\mathbf{5}^{\prime} \mathbf{-} \mathbf{3}^{\prime} \mathbf{)}\right.$ \\
\hline hno-F & CGGGATCCGATGACAGAAAAGATATATGATGC $($ BamHI) \\
hno-R & CCCAAGCTTTAAAGCGTCGCCTTC (HindIII) $)^{\mathrm{a}}$ \\
Primer A & CGCGGATCCATGACAGAAAAGATATATGATGC \\
Primer B & TCGATAAATGCGCGCTTTTAGGCTAGCTGCAACTCGTTC \\
Primer C & AAAAGCGCGCATTTATCGAACACGCCGAGATGGCTGAC \\
Primer D & GCCGGGCCCTTAAGCGGTCGCCTTC \\
Primer F2 & GCCGGGCCCCATGACAGAAAAGATATATGATGC (Apal) \\
Primer R2 & CGCGGATCCTTAAGCGGTCGCCTTC (BamHI) \\
\hline
\end{tabular}

${ }^{a}$ The restriction site is underlined

\section{Determination of the enzymatic reaction products}

To identify the reaction products catalyzed by Hno, purified Hno was mixed with $11.2 \mathrm{mM}$ 6-hydroxynicotine and $0.2 \mathrm{M} \mathrm{NaCl}$ in $1 \mathrm{~mL}$ of $50 \mathrm{mM}$ phosphate buffer $(\mathrm{pH}$ 7.0) instead of glycine- $\mathrm{NaOH}$ because glycine produces an absorption peak in HPLC analysis, causing a negative effect on products separation. The reaction mixture was incubated at $37{ }^{\circ} \mathrm{C}$ for $30 \mathrm{~min}$. The reaction was monitored by a UV-visible Ultrospec 2100 pro Spectrophotometer (GE Healthcare). The final products were identified by liquid chromatography-mass spectrometry (LC-MS) as described [24]. LC-MS data were obtained using a Finnigan Surveyor MSQ single quadrupole electrospray ionization mass spectrometer coupled with a Finnigan Surveyor HPLC (Finnigan/Thermo Electron Corporation, San Jose, CA, USA). Positively charged ions were detected. The HPLC system was equipped with an Agilent Eclipse XDB-C18 column (column size, $250 \times 4.6 \mathrm{~mm}$; particle size, $5 \mu \mathrm{M}$; Agilent, USA) and a PDA detector. A mixture of methanol and $12 \mathrm{mM}$ formic acid $(10: 90, \mathrm{v} / \mathrm{v})$ was used as the mobile phase, and the flow rate was set at $0.5 \mathrm{~mL} \mathrm{~min}^{-1}$.

\section{Deletion and complementation of the hno gene}

The deletion of the hno gene was performed using the in-frame deletion system based on homologous recombination [24]. First, a 503-bp upstream sequence (primers $A$ and $B$ in Table 3) and a 485-bp downstream sequence (primers $\mathrm{C}$ and $\mathrm{D}$ in Table 3 ) were amplified by PCR using the genome of $A$. tumefaciens S33 as template. The PCR products above were mixed together for another seven amplifying cycles to obtain truncated hno genes due to the 19-bp complementary sequences between primers $\mathrm{B}$ and $\mathrm{C}$. The truncated hno genes were used as a template for the third PCR to procure more of the shortened target genes and were then inserted into the suicide plasmid pJQ200SK with restriction sites BamHI and ApaI, generating the recombinant plasmid $\mathrm{pJQ}-\Delta h n o$. 
The recombinant plasmid pJQ- $\Delta$ hno was transferred into A. tumefaciens S33 by conjugation with the help of E. coli HB101(pRK2013). The mutant with single-crossover DNA exchange was obtained by the Gm-resistance screening. After culturing the mutant in HSP medium containing $20 \%$ sucrose $(\mathrm{w} / \mathrm{v})$, double-crossover DNA exchange was achieved, and the plasmid pJQ200SK with completed hno gene was removed, generating A. tumefaciens S33- $\Delta$ hno which is sensitive to $\mathrm{Gm}$.

To recover the activity of Hno for A. tumefaciens S33$\Delta h n o$, the complete hno genes were amplified from the genome of A. tumefaciens S33 using the primers F2 and R2 (see Table 3). The PCR products were digested by ApaI and BamHI and inserted into the plasmid of pBBR1MCS-5 with the same restriction sites to procure the complementation plasmid pBBR-hno. Then the recombinant plasmid was transferred into $A$. tumefaciens S33- $\Delta h n o$ through electroporation transformation (100 $\mu \mathrm{L}$ competent cells, $1 \mu \mathrm{g}$ plasmid DNA, $1.2 \mathrm{kV} \mathrm{cm}^{-1}$ field strength, $200 \Omega$ resistance, $25 \mu \mathrm{F}$ capacitance, BioRad Gene Pulser Xcell ${ }^{\mathrm{TM}}$ system, Hercules, CA, USA) [38], obtaining the complementation strain A. tumefaciens S33- $\Delta$ hno-C.

To further confirm the deletion of the hno gene, the wild-type strain A. tumefaciens S33, and the engineered strains, A. tumefaciens S33- $\Delta$ hno and A. tumefaciens S33- $\Delta$ hno-C, were cultured in LB, HSP, nicotine, and 6-hydroxynicotine media. For LB, HSP, and nicotine media, optical density (OD) at $620 \mathrm{~nm}$ was measured. For 6-hydroxynicotine medium, a solid agar plate was used to observe cell growth. Then the three strains were cultured in HSP medium or nicotine-glucose-ammonium medium. Cells were collected by centrifugation at $30,000 \times g$ for $10 \mathrm{~min}$ and disrupted by sonication. The Ndh and Hno activities were determined, as described above.

\section{Extraction of crude nicotine from tobacco waste}

The nicotine used as the substrate for the biotransformation reactions in this study was prepared from tobacco waste according to a previous report [12]. The tobacco waste containing 2.3\% (w/w) nicotine was obtained from the Yuxi Cigarrette Co. Ltd., Yunnan Province, China. Nicotine was separated by steam distillation, purified by extraction with chloroform, and then evaporation was used to recover the solvent. The final product contained 94-97\% nicotine.

\section{Test of the reaction catalyzed by the whole cells of $A$.} tumefaciens S33- $\mathbf{H}$ no

To test the possibility of biotransformation of nicotine into 6-hydroxynicotine, the whole cells $\left(\sim 1.45 \mathrm{~g} \mathrm{~L}^{-1}\right.$ DCW) of A. tumefaciens S33- $\Delta h n o$ were used as a catalyst. These cells were prepared by growing in nicotine-glucose-ammonium medium for $24 \mathrm{~h}$. The reaction was performed at $30^{\circ} \mathrm{C}$ in $50 \mathrm{mM}$ sodium phosphate buffer ( $\mathrm{pH} 7.0$ ) with $0.85 \mathrm{~g} \mathrm{~L}^{-1}$ nicotine as the substrate. Concentrations of nicotine and the expected product 6-hydroxynicotine were determined by HPLC (Agilent 1100 system, equipped with an Eclipse XDB-C18 column and a PDA detector). The mobile phase included methanol and $8 \mathrm{mM}$ formic acid $(10: 90, \mathrm{v} / \mathrm{v})$ with a flow rate of $0.5 \mathrm{~mL} \mathrm{~min}^{-1}$ at $30^{\circ} \mathrm{C}$.

\section{Optimization of the reaction conditions for the biotransformation of nicotine into 6-hydroxynicotine by whole cells of $A$. tumefaciens S33- $\Delta$ hno}

To improve the catalytic rate to produce 6-hydroxynicotine, different reaction conditions were examined. Routinely, the reactions were carried out at $30{ }^{\circ} \mathrm{C}$ in $50 \mathrm{mM}$ sodium phosphate buffer ( $\mathrm{pH} 7.0)$ with $1.0 \mathrm{~g} \mathrm{~L}^{-1}$ nicotine as the substrate and $\sim 1.5 \mathrm{~g} \mathrm{~L}^{-1} \mathrm{DCW}$ whole cells of $A$. tumefaciens S33- $\Delta h n o$ as a catalyst, which were grown in nicotine-glucose-ammonium medium for $24 \mathrm{~h}$. The examined reaction conditions were as follows: The amount of $A$. tumefaciens S33- $\Delta$ hno whole cells used for the catalyst was tested in a range from 0.3 to $4.8 \mathrm{~g} \mathrm{~L}^{-1} \mathrm{DCW}$. The tested initial concentration of nicotine increased from 1 to $16 \mathrm{~g} \mathrm{~L}^{-1}$. The buffers used were changed from $\mathrm{pH} 6.0$ to 10.0 , where $50 \mathrm{mM}$ sodium phosphate buffer ( $\mathrm{pH} 6.0$ and $\mathrm{pH} 7.0), 50 \mathrm{mM}$ Tris- $\mathrm{HCl}$ buffer ( $\mathrm{pH} 8.0$ ), and $50 \mathrm{mM}$ glycine- $-\mathrm{NaOH}$ buffer (pH 9.0 and $\mathrm{pH} 10.0$ ) were prepared. The catalytic temperature varied from $16{ }^{\circ} \mathrm{C}$ to $44{ }^{\circ} \mathrm{C}$. The oxygen requirement was tested in a rotary shaker with the rotation speed set at $0,100,200$, or $250 \mathrm{rpm}$. Moreover, to obtain the biocatalyst with the highest activity, various media were tested for growing $A$. tumefaciens S33- $\Delta h n o$ including HSP medium, glucose-ammonium medium, LB medium, and all these media plus $0.1 \mathrm{~g} \mathrm{~L}^{-1}$ of HSP or nicotine. The amounts of the substrate and product in the reaction mixtures were measured by HPLC as above.

\section{Batch and fed-batch biotransformation}

To re-utilize the biocatalyst, batch and fed-batch biotransformation were tried. Cells of A. tumefaciens S33- $\Delta$ hno $\left(\sim 1.0 \mathrm{~g} \mathrm{~L}^{-1} \mathrm{DCW}\right)$, cultured with glucoseammonium medium plus $0.1 \mathrm{~g} \mathrm{~L}^{-1} \mathrm{HSP}$, were added as a catalyst to $200 \mathrm{~mL}$ of $50 \mathrm{mM}$ sodium phosphate buffer (pH 7.0) containing $1.0 \mathrm{~g} \mathrm{~L}^{-1}$ nicotine. The reaction was performed at $30{ }^{\circ} \mathrm{C}$ with a speed of $200 \mathrm{rpm}$. For the batch biotransformation, the biocatalyst was recycled by centrifugation to collect the cells and then was re-used three times. For the fed-batch biotransformation, nicotine was supplemented three times at a concentration 
of $1.0 \mathrm{~g} \mathrm{~L}^{-1}$ after the substrate was almost completely consumed.

\section{Extraction and purification of the product 6-hydroxynicotine}

After the reaction finished, the supernatant was obtained by centrifugation at $10,000 \times g$ for $10 \mathrm{~min}$ and adjusted to $\mathrm{pH} 10.5$ with $2 \mathrm{M} \mathrm{NaOH}$. Then the supernatant was concentrated by rotary evaporation under reduced pressure at $60{ }^{\circ} \mathrm{C}$. The product 6 -hydroxynicotine was extracted from the concentrate with equal volume of dichloromethane for three times. The extracts were pooled, and then was dried using $\mathrm{Na}_{2} \mathrm{SO}_{4}$. The solvent was removed further by evaporation. The isolated product was identified by recording the UV-visible absorption spectra after being dissolved in a $0.1-\mathrm{M} \mathrm{HCl}$ solution and determining its mass spectrometry by LC-MS on the Dionex's UltiMate 3000 UHPLC-Bruker's impact HD high-resolution mass spectrometry system. The same column and chromatography conditions used above were applied. The NMR spectra were recorded for solutions in $\mathrm{CDCl}_{3}$ on an AVANCE 600 spectrometer (Bruker, Switzerland) operating at $600 \mathrm{MHz}$ for ${ }^{1} \mathrm{H}$ and at $150 \mathrm{MHz}$ for ${ }^{13} \mathrm{C}$.

\section{Nucleotide sequence accession numbers}

The A. tumefaciens S33 genome GenBank accession numbers are CP014259.1 and CP014260.1.

\section{Additional file}

Additional file 1: Figure S1. NMR spectra of the product 6-hydroxynicotine. a ${ }^{1} \mathrm{H}-\mathrm{NMR}$ spectrum $\left(\mathrm{CDCl}_{3}, 600 \mathrm{MHz}\right) \cdot \mathbf{b}{ }^{13} \mathrm{C}-\mathrm{NMR}$ spectrum $\left(\mathrm{CDCl}_{3}\right.$, $150 \mathrm{MHz}$ ). Figure S2. NMR spectra of the authentic commercial standard 6-hydroxynicotine. a ${ }^{1} \mathrm{H}-\mathrm{NMR}$ spectrum $\left(\mathrm{CDCl}_{3}, 600 \mathrm{MHz}\right) \cdot \mathbf{b}^{13} \mathrm{C}-\mathrm{NMR}$ spectrum $\left(\mathrm{CDCl}_{3}, 150 \mathrm{MHz}\right)$.

\section{Abbreviations}

DCIP: 2,6-dichlorophenolindophenolsodium; DCW: dry cell weight; FPKM: fragments per kilobase per million; Hno: 6-hydroxynicotine oxidase; HSP: 6-hydroxy-3-succinoylpyridine; IPTG: isopropyl- $\beta$-D-thiogalactopyranoside; NdhAB: nicotine dehydrogenase; OD: optical density; PDA: photodiode array; rpm: rev $\mathrm{min}^{-1}$.

\section{Authors' contributions}

SW, WY, HH, and $H X$ designed the experiments, analyzed the data, and wrote the manuscript. WY, RW, HL, JL, and YW performed the experiments. All authors discussed the results and commented on the manuscript. All authors read and approved the final manuscript.

\section{Author details \\ 'State Key Laboratory of Microbial Technology, School of Life Science, Shan- dong University, Jinan 250100, People's Republic of China. ${ }^{2}$ Institute of Basic Medicine, Shandong Academy of Medical Science, Jinan 250062, People's Republic of China. ${ }^{3}$ Environment Research Institute, Shandong University, Jinan 250100, People's Republic of China.}

\section{Acknowledgements}

We thank Professor Ping Xu from Shanghai Jiao Tong University for his valuable supports. We also thank Caiyun Sun, Jing Zhu, and Zhifeng Li from
Analysis and Testing Center of SKLMT (State Key Laboratory of Microbial Technology, Shandong University) for assistance in HPLC and LC-MS analyses. This work was supported by the grant from the Fundamental Research Funds of Shandong University (Grant No. 2014JC023).

\section{Competing interests}

The authors declare that they have no competing interests.

Availability of data and materials

All data generated or analyzed during this study are included in this article and its Additional files.

\section{Ethics approval and consent to participate}

Not applicable.

\section{Publisher's Note}

Springer Nature remains neutral with regard to jurisdictional claims in published maps and institutional affiliations.

Received: 4 August 2017 Accepted: 26 November 2017

Published online: 04 December 2017

\section{References}

1. Civilini M, Domenis C, Sebastianutto N, de Berfoldi M. Nicotine decontamination of tobacco agro-industrial waste and its degradation by micro-organisms. Waste Manag Res. 1997;15:349-58.

2. Novotny TE, Zhao F. Consumption and production waste: another externality of tobacco use. Tob Control. 1999;8(1):75-80.

3. Food and Agriculture Organization. Projections of tobacco production, consumption and trade to the year 2010. Rome: Food and Agriculture Organization of the United Nations; 2003.

4. Wang $\mathrm{SN}$, Liu Z, Xu P. Biodegradation of nicotine by a newly isolated Agrobacterium sp. strain S33. J Appl Microbiol. 2009;107(3):838-47.

5. Campain JA. Nicotine: potentially a multifunctional carcinogen? Toxicol Sci. 2004;79(1):1-3.

6. Benowitz NL. Nicotine addiction. N Engl J Med. 2010;362(24):2295-303.

7. Hecht SS. Tobacco smoke carcinogens and lung cancer. J Natl Cancer Inst. 1999:91(14):1194-210.

8. Iranpour R, Stenstrom M, Tchobanoglous G, Miller D, Wright J, Vossoughi $M$. Environmental engineering: energy value of replacing waste disposal with resource recovery. Science. 1999;285(5428):706-11.

9. Roduit JP, Wellig A, Kiener A. Renewable functionalized pyridines derived from microbial metabolites of the alkaloid (S)-nicotine. Heterocycles. 1997;45:1687-702.

10. Schmid A, Dordick JS, Hauer B, Kiener A, Wubbolts M, Witholt B. Industrial biocatalysis today and tomorrow. Nature. 2001;409(6817):258-68.

11. Wang S, Huang H, Xie K, Xu P. Identification of nicotine biotransformation intermediates by Agrobacterium tumefaciens strain S33 suggests a novel nicotine degradation pathway. Appl Microbiol Biotechnol. 2012;95(6):1567-78.

12. Wang SN, Xu P, Tang HZ, Meng J, Liu XL, Ma CQ. "Green" route to 6-hydroxy-3-succinoyl-pyridine from (S)-nicotine of tobacco waste by whole cells of a Pseudomonas sp. Environ Sci Technol. 2005;39(17):6877-80.

13. Wang $W, X u$ P, Tang H. Sustainable production of valuable compound 3-succinoyl-pyridine by genetically engineering Pseudomonas putida using the tobacco waste. Sci Rep. 2015;5:16411.

14. Yu H, Tang H, Xu P. Green strategy from waste to value-added-chemical production: efficient biosynthesis of 6-hydroxy-3-succinoyl-pyridine by an engineered biocatalyst. Sci Rep. 2014:4:5397.

15. Spande TF, Garraffo HM, Edwards MW, Yeh HJC, Pannell L, Daly JW. Epibatidine: a novel (chloropyridyl)azabicycloheptane with potent analgesic activity from an Ecuadoran poison frog. J Am Chem Soc. 1992:114(9):3475-8.

16. Hritcu L, Stefan M, Brandsch R, Mihasan M. Enhanced behavioral response by decreasing brain oxidative stress to 6-hydroxy-L-nicotine in Alzheimer's disease rat model. Neurosci Lett. 2015:591:41-7. 
17. Malphettes L, Schoenmakers RG, Fussenegger M. 6-Hydroxy-nicotineinducible multilevel transgene control in mammalian cells. Metab Eng. 2006;8(6):543-53.

18. Edward B. Derivatives of 6-hydroxynicotine. United States Patent. US 3,230,226. Jan 18, 1966.

19. Squires WC, Hayes LE. Synthesis of 6-hydroxynicotine. United States Patent. US 3,644,176. Feb 22, 1972.

20. Ishige T, Honda K, Shimizu S. Whole organism biocatalysis. Curr Opin Chem Biol. 2005:9(2):174-80.

21. Schoemaker HE, Mink D, Wubbolts MG. Dispelling the myths-biocatalysis in industrial synthesis. Science. 2003:299(5613):1694-7.

22. Zheng GW, Xu JH. New opportunities for biocatalysis: driving the synthesis of chiral chemicals. Curr Opin Biotechnol. 2011;22(6):784-92.

23. Yu W, Wang $\mathrm{R}$, Huang $\mathrm{H}$, Xie H, Wang S. Periplasmic nicotine dehydrogenase NdhAB utilizes pseudoazurin as its physiological electron acceptor in Agrobacterium tumefaciens S33. Appl Environ Microbiol. 2017;83(17):e01050-17. https://doi.org/10.1128/AEM.01050-17.

24. Li H, Xie K, Yu W, Hu L, Huang H, Xie H, Wang S. Nicotine dehydrogenase complexed with 6-hydroxypseudooxynicotine oxidase involved in the hybrid nicotine-degrading pathway in Agrobacterium tumefaciens S33. Appl Environ Microbiol. 2016;82(6):1745-55.

25. Huang $H$, Yu W, Wang R, Li H, Xie H, Wang S. Genomic and transcriptomic analyses of Agrobacterium tumefaciens S33 reveal the molecular mechanism of a novel hybrid nicotine-degrading pathway. Sci Rep. 2017;7(1):4813

26. Yu W, Li H, Xie K, Huang H, Xie H, Wang S. Genome sequence of the nicotine-degrading Agrobacterium tumefaciens S33. J Biotechnol. 2016;228:1-2.

27. Qiu J, Wei Y, Ma Y, Wen R, Wen Y, Liu W. A novel (S)-6-hydroxynicotine oxidase gene from Shinella sp. strain HZN7. Appl Environ Microbiol. 2014;80(18):5552-60.

28. Yu H, Tang H, Zhu X, Li Y, Xu P. Molecular mechanism of nicotine degradation by a newly isolated strain, Ochrobactrum sp. strain SJY1. Appl Environ Microbiol. 2015;81(1):272-81.

29. Qiu J, Ma Y, Zhang J, Wen Y, Liu W. Cloning of a novel nicotine oxidase gene from Pseudomonas sp. strain HZN6 whose product nonenantioselectively degrades nicotine to pseudooxynicotine. Appl Environ Microbiol. 2013;79(7):2164-71.
30. Tang H, Wang L, Wang W, Yu H, Zhang K, Yao Y, Xu P. Systematic unraveling of the unsolved pathway of nicotine degradation in Pseudomonas. PLoS Genet. 2013:9(10):e1003923.

31. Dai VD, Decker K, Sund H. Purification and properties of L-6-hydroxynicotine oxidase. Eur J Biochem. 1968:4(1):95-102.

32. Igloi GL, Brandsch R. Sequence of the 165-kilobase catabolic plasmid pAO1 from Arthrobacter nicotinovorans and identification of a pAO1dependent nicotine uptake system. J Bacteriol. 2003;185(6):1976-86.

33. Decker K, Dai VD. Mechanism and specifcity of L- and D-6-hydroxynicotine oxidase. Eur J Biochem. 1967;3(2):132-8.

34. Hochstein LI, Rittenberg SC. The bacterial oxidation of nicotine. II. The isolation of the first oxidative product and its identification as (1)-6-hydroxynicotine. J Biol Chem. 1959;234(1):156-60.

35. Li H, Xie K, Huang H, Wang S. 6-Hydroxy-3-succinoylpyridine hydroxylase catalyzes a central step of nicotine degradation in Agrobacterium tumefaciens S33. PLOS ONE. 2014:9(7):e103324.

36. Brühmüller M, Mohler H, Decker K. Covalently bound flavin in D-6-hydroxynicotine oxidase from Arthrobacter oxidans. Purification and properties of D-6-hydroxynicotine oxidase. Eur J Biochem. 1972;29(1):143-51.

37. Bradford MM. A rapid and sensitive method for the quantitation of microgram quantities of protein utilizing the principle of protein-dye binding Anal Biochem. 1976:72:248-54.

38. Wise AA, Liu Z, Binns AN. Three methods for the introduction of foreign DNA into Agrobacterium. Methods Mol Biol. 2006;343:43-53.

39. Quandt J, Hynes MF. Versatile suicide vectors which allow direct selection for gene replacement in gram-negative bacteria. Gene. 1993;127(1):15-21.

40. Kovach ME, Elzer PH, Hill DS, Robertson GT, Farris MA, Roop RM II, Peterson KM. Four new derivatives of the broad-host-range cloning vector PBBR1MCS, carrying different antibiotic-resistance cassettes. Gene. 1995;166(1):175-6.

\section{Submit your next manuscript to BioMed Central and we will help you at every step:}

- We accept pre-submission inquiries

- Our selector tool helps you to find the most relevant journal

- We provide round the clock customer support

- Convenient online submission

- Thorough peer review

- Inclusion in PubMed and all major indexing services

- Maximum visibility for your research

Submit your manuscript at www.biomedcentral com/submit 